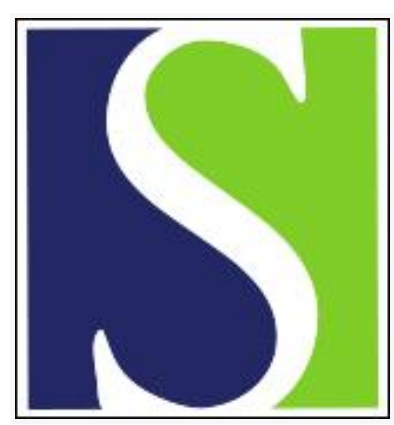

Scand J Work Environ Health 1990;16(2):102-107

https://doi.org/10.5271/sjweh.1811

Issue date: 01 Apr 1990

Risk of spontaneous abortion among nurses handling antineoplastic drugs.

by Stucker I, Caillard JF, Collin R, Gout M, Poyen D, Hemon D

Affiliation: Unite de Recherches Epidemiologiques et Statistiques sur I'Environnement et la Sante, Villejuif, France.

This article in PubMed: www.ncbi.nlm.nih.gov/pubmed/2353192

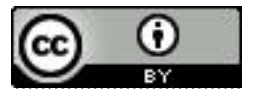




\title{
Risk of spontaneous abortion among nurses handling antineoplastic drugs
}

\author{
by Isabelle Stücker, $\mathrm{PhD},{ }^{1}$ Jean-François Caillard, MD, ${ }^{2}$ Renée Collin, MD, ${ }^{3}$ \\ Michèle Gout, MD, ${ }^{4}$ Danièle Poyen, MD, ${ }^{5}$ Denis Hémon, $\mathrm{PhD}^{1}$
}

\begin{abstract}
STÜCKER I, CAILLARD J-F, COLLIN R, GOUT M, POYEN D, HÉMON D. Risk of spontaneous abortion among nurses handling antineoplastic drugs. Scand J Work Environ Health 1990;16:102-7. The purpose of the study was to evaluate the frequency of spontaneous abortion in two groups of women. One group consisted of women regularly involved in the preparation of cancer chemotherapy perfusions and therefore considered to be exposed to cytostatic agents; the other consisted of women not occupationally exposed to such agents. The study was carried out in four French hospitals. Four hundred and sixty-six women were involved; 534 pregnancies were described in which 139 were exposed and 357 were unexposed. The results showed that the frequency of spontaneous abortion was $26 \%$ for the exposed pregnancies and $15 \%$ in the unexposed ones (odds ratio 2.0 ). These results do not seem to be due either to the classic risk factors of spontaneous abortion (age, cigarette consumption during pregnancy, pregnancy order) (adjusted odds ratio 1.7) or to possible errors concerning the retrospective evaluation of prior gynecologic and obstetric history.
\end{abstract}

Key terms: cytostatics, occupation, pregnancy outcome, reproductive hazard.

Cytostatics are chemical agents which, because of their antimitotic action, are often used in cancer chemotherapy. Their mutagenicity, carcinogenicity, and teratogenicity have been amply documented by in vitro and in vivo experiments $(1,2)$. Some particular agents, especially methotrexate, have been shown to be teratogenic in pregnant women being treated by cancer chemotherapy $(3,4)$. Moreover the relationship between the mechanisms of mutagenesis and teratogenesis have been emphasized by several authors $(5,6)$.

Several studies concerned with occupational exposure to these agents have shown a significant increase in urine mutagenicity in exposed subjects as compared with unexposed subjects (7-11). Other studies have demonstrated that work preparing cytostatic perfusions can lead to an increase in the average number of sister chromatid exchanges and to an increase in the frequency of chromosome anomalies in lymphocytes (12-14). To our knowledge four studies provide some epidemiologic information on the relationship between cytostatic exposure and reproductive hazards $(15-18)$.

1 Unité de Recherches Epidémiologiques et Statistiques sur l'Environnement et la Santé, Villejuif Cedex, France.

2 Preventive Medicine Department, Regional Hospital of Rouen, Rouen, France.

3 Preventive Medicine Department, Regional Hospital of Grenoble, Grenoble, France.

4 Preventive Medicine Department of Institut Gustave Roussy, Villejuif, France.

5 Preventive Medicine Department, Regional Hospital of Marseille, Marseille, France.

Reprint requests to: Dr I Stücker, Unité de Recherches Epidémiologiques et Statistiques sur l'Environnement et la Santé, INSERM U170, 16 Avenue Paul Vaillant Couturier, 94807 Villejuif Cedex, France.
McDonald et al, in the frame of a case-referent survey on spontaneous abortions in a large general population, did not find a significant relationship between cytostatic exposure and spontaneous abortion (15). Taskinen et al observed an increased risk among potentially exposed pregnancies, which was however not statistically significant, in a case-referent study in the pharmaceutical industry (16). The case-referent study of Hemminki et al (17) was performed within a cohort of hospital nurses and did not show any increased risk of spontaneous abortion among nurses exposed to cytostatics. However, restricting their population to specialized departments where cytostatic exposure can be thought to be higher, Hemminki et al (17) showed a significantly higher risk of congenital malformations in relation to this exposure. Finally, Selevan et al (18), who performed a case-referent study within a cohort of nurses working in oncologic departments, observed a twofold increase in the risk of spontaneous abortion among exposed nurses.

The present study was aimed at evaluating the possible modifications of parameters characteristic of the reproductive function in relation to the handling of cytostatic drugs. The presented results concern the frequency of spontaneous abortion in two groups of nurses, one in which the nurses prepared cancer chemotherapy perfusions and the other one in which they did not.

\section{Subjects and methods}

The frequency of spontaneous abortion was compared between the previous pregnancies of a group of nurses handling perfusions in cancer treatment units and those 
of a group of nurses who were not so exposed. The data were collected by interview from May 1985 to May 1986 in three French hospitals and in a large center for cancer treatment.

\section{Choice of medical departments and eligibility of the subjects}

The cancer units selected were those in which the number of cytostatic phials distributed annually by the hospital pharmacy corresponded to a minimum of ten cytostatic perfusions prepared per week and per nurse. Consulting medical, cardiologic, endocrinologic, and general medical units were chosen as the reference units. All the female daytime nursing staff (head nurses, registered nurses, practical nurses) aged 45 years or less and working in one of the selected units were asked to participate.

\section{Collection of information}

In each center, interviews were carried out by an investigating physician. The questionnaire consisted of the following three parts: (i) general characteristics of the subject; (ii) description of pregnancies and classical risk factors involved in spontaneous abortions (pregnancy order, age of the mother at pregnancy, and cigarette consumption); and (iii) job held by the subject at the time of the study and previous jobs, including those outside the medical field. To be able to evaluate the reliability of the spontaneous abortions reported, the subjects were asked to define the method used to diagnose the pregnancy (laboratory examination, pharmaceutical test, physician examination or late menstrual period), the number of weeks of gestation at abortion, and the occurrence of hospitalization or curettage. A spontaneous abortion was defined as a pregnancy which ended before 28 weeks of gestation. In order to avoid the underreporting of induced abortions, we preferred to exclude them from the interview. Therefore, the frequency of spontaneous abortion was defined as the rate of the number of spontaneous abortions over the number of pregnancies, excluding induced abortions.

The questionnaire enabled us to date precisely occupational exposure to cytostatics drugs, anesthetic agents, and formaldehyde. Any pregnancy occurring after or during a period of exposure to cytostatics was considered to be "exposed." Similarly, pregnancies occurring after exposure to formaldehyde or anesthetic agents were considered to be exposed to the respective substance. Exposure to cytostatics was further described according to the frequency (regular, occasional, rare) and total duration of exposure. At the time of the study, no special protective equipment, such as a fume hood, was in operation. Furthermore, the use of personal protective equipment (surgical gloves and masks) was not uniform among the nurses, concerned only a few drugs (methotrexate), and was a recent concern for the nurses.

\section{Statistical analysis}

In all the statistical analyses the different pregnancies of the same woman were considered to be statistically independent, even though this is not strictly true. Statistical analysis was thus also carried out solely for first pregnancies to take into account the variability in the risk of spontaneous abortion between women.

\section{Results}

Of the 535 women eligible for the study, 39 could not be contacted due to temporary leave of absence (sick leave, maternity leave, holiday, professional training), and 30 refused to participate. The study therefore involved 466 women (rate of participation $87 \%$ ), 271 belonging to units in which cytostatics were handled and 195 to control units. The general characteristics of the women who participated are presented in table 1 , and those of the 534 reported pregnancies are shown in table 2.

For 38 pregnancies there was no available information to enable the determination of cytostatic exposure. Among the 496 remaining pregnancies, for which exposure information was available, there was no ex-

Table 1. Characteristics of the population.

\begin{tabular}{|c|c|c|c|c|}
\hline Characteristic & $\mathrm{N}$ & $\%$ & Mean & SD \\
\hline Total population & 466 & . & . & $\cdot$ \\
\hline Age at interview (years) & . & . & 31.2 & 6.5 \\
\hline $\begin{array}{l}\text { Length of work period } \\
\text { in department (years) }\end{array}$ & . & . & 4.6 & 4.3 \\
\hline $\begin{array}{l}\text { Length of total work period } \\
\text { (years) }\end{array}$ & . & . & 9.7 & 6.5 \\
\hline Percentage of exposed nurses & . & 36.5 & . & . \\
\hline Exposed nurses & 170 & . & . & . \\
\hline \multicolumn{5}{|l|}{$\begin{array}{l}\text { Frequency of exposure } \\
\text { to cytostatics }\end{array}$} \\
\hline $\begin{array}{l}\text { Regular } \\
\text { Occasional } \\
\text { Rare }\end{array}$ & $\begin{array}{r}153 \\
14 \\
3\end{array}$ & $\dot{.}$ & . & $\dot{.}$ \\
\hline $\begin{array}{l}\text { Time of prior exposure } \\
\text { to cytostatics (years) }\end{array}$ & $\cdot$ & · & 6.1 & 6.5 \\
\hline $\begin{array}{l}\text { Number of perfusions prepared } \\
\text { per week by each nurse }\end{array}$ & . & . & 18.6 & 2.2 \\
\hline
\end{tabular}

Table 2. Characteristics of the reported pregnancies.

\begin{tabular}{|c|c|c|c|c|}
\hline Characteristic & $\mathrm{N}$ & $\%$ & Mean & SD \\
\hline $\begin{array}{l}\text { Total number of pregnancies } \\
\text { described }\end{array}$ & 534 & . & . & $\cdot$ \\
\hline Nullipara women & . & 43.1 & . & $\cdot$ \\
\hline $\begin{array}{l}\text { Age of mother at pregnancy } \\
\text { (years) }\end{array}$ & . & . & 25.1 & 4.3 \\
\hline Pregnancy order & - & . & 1.8 & 1.1 \\
\hline $\begin{array}{l}\text { Frequency of spontaneous } \\
\text { abortions }\end{array}$ & . & 19.9 & . & $\cdot$ \\
\hline $\begin{array}{l}\text { Length of pregnancy before } \\
\text { spontaneous abortion (weeks) }\end{array}$ & . & . & 8.1 & 3.8 \\
\hline
\end{tabular}


Table 3. Frequency of spontaneous abortion and exposure to cytostatics drugs.

\begin{tabular}{|c|c|c|c|c|c|c|}
\hline & \multicolumn{2}{|c|}{$\begin{array}{l}\text { Exposed } \\
\text { pregnancies }\end{array}$} & \multicolumn{2}{|c|}{$\begin{array}{l}\text { Unexposed } \\
\text { pregnancies }\end{array}$} & \multirow{2}{*}{$\begin{array}{l}\text { Rate } \\
\text { ratio }\end{array}$} & \multirow{2}{*}{$\begin{array}{c}95 \% \\
\text { confidenc } \\
\text { interval }\end{array}$} \\
\hline & $\mathrm{N}$ & $\%$ & $\mathrm{~N}$ & $\%$ & & \\
\hline All pregnancies & 139 & 25.9 & 357 & 15.1 & 1.7 & $1.2-2.5$ \\
\hline First pregnancy only & 66 & 22.7 & 184 & 10.3 & 2.2 & $1.2-4.1$ \\
\hline $\begin{array}{l}\text { Pregnancies with no previous } \\
\text { exposure to anesthetic agents }\end{array}$ & 132 & 25.8 & 340 & 15.0 & 1.7 & $1.2-2.5$ \\
\hline $\begin{array}{l}\text { Pregnancies with no previous } \\
\text { exposure to formaldehyde }\end{array}$ & 106 & 25.5 & 277 & 11.9 & 2.1 & $1.3-3.4$ \\
\hline
\end{tabular}

Table 4. Characteristics of the spontaneous abortions and the births with respect to risk factors. (SE = standard error of the mean)

\begin{tabular}{|c|c|c|c|c|c|c|}
\hline \multirow[t]{2}{*}{ Characteristic } & \multicolumn{3}{|c|}{$\begin{array}{c}\text { Spontaneous } \\
\text { abortions } \\
(\mathrm{N}=106)\end{array}$} & \multicolumn{3}{|c|}{$\begin{array}{l}\text { Births } \\
(N=428)\end{array}$} \\
\hline & $\%$ & Mean & SE & $\%$ & Mean & SE \\
\hline $\begin{array}{l}\text { Age of mother at } \\
\text { pregnancy (years) }\end{array}$ & $\cdot$ & 27.1 & 0.5 & . & 24.7 & 0.2 \\
\hline $\begin{array}{l}\text { Age at pregnancy } \\
>30 \text { years }\end{array}$ & 20.8 & $\cdot$ & · & 8.5 & $\cdot$ & $\cdot$ \\
\hline Pregnancy order & . & 2.2 & 0.1 & $\cdot$ & 1.7 & 0.1 \\
\hline $\begin{array}{l}\text { Second or higher } \\
\text { in the order of } \\
\text { pregnancies }\end{array}$ & 62.2 & $\cdot$ & $\cdot$ & 47.2 & - & $\cdot$ \\
\hline $\begin{array}{l}\text { Smokers during } \\
\text { pregnancy }\end{array}$ & 22.2 & $\cdot$ & · & 11.0 & · & $\cdot$ \\
\hline
\end{tabular}

Table 5. Characteristics of exposed and unexposed pregnancies with respect to risk factors. $(\mathrm{SE}=\mathrm{standard}$ error of the mean)

\begin{tabular}{|c|c|c|c|c|c|c|}
\hline \multirow[t]{2}{*}{ Characteristic } & \multicolumn{3}{|c|}{$\begin{array}{c}\text { Exposed } \\
\text { pregnancies } \\
(\mathrm{N}=139)\end{array}$} & \multicolumn{3}{|c|}{$\begin{array}{l}\text { Unexposed } \\
\text { pregnancies } \\
(\mathrm{N}=357)\end{array}$} \\
\hline & $\%$ & Mean & SE & $\%$ & Mean & SE \\
\hline $\begin{array}{l}\text { Age of mother at } \\
\text { pregnancy (years) }\end{array}$ & $\cdot$ & 27.1 & 0.3 & · & 24.4 & 0.2 \\
\hline $\begin{array}{l}\text { Age at pregnancy } \\
>30 \text { years }\end{array}$ & 18.0 & $\cdot$ & . & 8.2 & . & . \\
\hline Pregnancy order & . & 1.8 & 0.08 & . & 1.5 & 0.05 \\
\hline $\begin{array}{l}\text { Second or higher } \\
\text { in the order of } \\
\text { pregnancies }\end{array}$ & 47.5 & · & · & 52.4 & · & · \\
\hline $\begin{array}{l}\text { Smokers during } \\
\text { pregnancy }\end{array}$ & 15.9 & $\cdot$ & · & 12.1 & . & . \\
\hline
\end{tabular}

posure in 357 cases, exposure only prior to pregnancy in 24, exposure during pregnancy in 7 , exposure both prior to and during pregnancy in 105 , and exposure for an undetermined time in 3 .

Because of the small numbers, it was impossible to analyze the effects of exposure before and during pregnancy separately. We therefore combined all the exposed pregnancies $(\mathrm{N}=139)$.

The frequency of spontaneous abortion was significantly higher in the exposed group $(25.9 \%)$ than in the unexposed one $(15.1 \%)(P<0.01)$. This result was also observed when the analysis was limited to the first pregnancy of each woman (table 3 ).

A comparison of the reported gestational ages at the time of the abortion did not reveal any significant difference between the exposed and unexposed groups.

The relationships between the occurrence of spontaneous abortion and well-known risk factors are described in table 4 . All of them were found to be statistically significant in the present sample. The occurrence of some of these factors was significantly different between the exposed and unexposed groups (table 5). Adjustment for smoking during pregnancy on one hand, and for age at pregnancy on the other, did not explain the observed relationship between exposure and the frequency of spontaneous abortion. Furthermore this relationship was still statistically significant when restricted to the first pregnancy of each woman. Adjustment for all these confounders (age at pregnancy, pregnancy order, smoking during pregnancy) simultaneously in a logistic regression decreased the odds ratio of the association from $2.0[95 \%$ confidence interval $(95 \% \mathrm{Cl}) 1.2-3.1]$ to $1.7(95 \% \mathrm{CI}$ $1.0-2.8$ ) without modifying the statistical significance.

The pregnancies could have been exposed to formaldehyde or to anesthetic agents. A pregnancy was considered exposed to formaldehyde if it occurred during or after exposure, defined as daily or frequent, to formol in connection with the disinfection of rooms and/or equipment. Previous exposure was thus found to be negative for 383 pregnancies and positive for 50 , the formaldehyde exposure of the remaining 63 being unknown. When the 113 pregnancies for which formaldehyde exposure was positive or unknown were excluded, the results concerning cytostatics were not modified (table 3 ). Similarly, excluding the 24 pregnancies with positive $(\mathrm{N}=10)$ or unknown $(\mathrm{N}=14)$ previous exposure to anesthetic agents from the analysis did not modify the results either (table 3 ).

Finally, in order to improve the social homogeneity of the sample, the analysis was restricted to pregnancies of head nurses and registered nurses only (practical nurses being excluded). The results again demonstrated a statistically significant excess of spontaneous abortions among the exposed pregnancies in comparison with the rate among the unexposed ones. 
In order to reduce the likelihood of bias due to an underreporting of spontaneous abortion, we excluded the ten spontaneous abortions corresponding to pregnancies diagnosed solely by the women themselves on the basis of late menstrual periods and spontaneous abortions which occurred after less than eight weeks without a menstrual period from the analysis. In both cases the frequency of spontaneous abortion was twice as high among the exposed pregnancies as among the unexposed ones $(\mathrm{P}<0.01)$. The same observation was made after the exclusion of extrauterine pregnancies. Finally, all these results were substantiated when only first pregnancies were assessed alone.

The frequency of spontaneous abortions did not display a statistically significant association with duration of exposure to cytostatic drugs prior to pregnancy $(28,24$, and $24 \%$ of the spontaneous abortions for $1-24,25-60$, and $>60$ months of exposure prior to pregnancy, respectively). Excluding the 24 pregnancies exposed only prior to pregnancy did not modify the results (rate ratio $1.7,95 \%$ CI $1.1-2.5$ ). Such was also the case for the relationship between spontaneous abortions and the frequency of exposure to cytostatic drugs during pregnancy.

\section{Discussion}

The purpose of this study was to compare the frequency of spontaneous abortion in relation to the handling of cytostatics. A pregnancy was defined as being exposed if the woman had, prior to or during pregnancy, given perfusions in departments where the handling of cytostatics was frequent at the time of the study (18 perfusions per week per nurse prepared on the average).

Spontaneous abortions were approximately twice as frequent among the exposed pregnancies than among the unexposed ones. McDonald's population-based case-referent study did not show any significant relationship between cytostatic exposure and spontaneous abortion (15). It may be thought however that McDonald's definition of cytostatic exposure could only be much broader than the one adopted in the present study, which concerned oncologic departments only. Taskinen et al's study (16) of women working in the pharmaceutical industry showed an odds ratio of 2.8 in relation with cytostatic exposure. The number of exposed subjects in their study was small however, and this association was not statistically significant. Hemminki et al's case-referent study (17) on spontaneous abortion was performed in a population of hospital nurses, and no significant association with cytostatic exposure was observed. However, restricting their population to nurses working in departments with frequent exposure to cytostatics, this group of researchers found a significant excess of malformed children among the exposed nurses. Finally, in a casereferent study performed within a population of nurses working in oncology departments, Selevan et al (18) observed an increase in the frequency of handling cytostatics in the group of subjects who had experienced spontaneous abortions in comparison with a group of subjects who had given birth. The results of their study, which is the most closely comparable to the present one as far as the definition of exposure is concerned, showed a risk of spontaneous abortion that was approximately twice as high for the exposed women as in our study.

\section{Selection bias}

In this study it was not technically possible to include subjects having previously worked in the departments in question and having since left the hospital. Axelsson (19) observed that women leave work more frequently after giving birth than after a spontaneous abortion (19). The rate of spontaneous abortion could therefore have been overestimated among the women remaining in the departments. It is however very unlikely in the present study that the influence of the outcome of pregnancy on subsequent employment differed for the exposed and unexposed women. It can therefore be thought that, if the rate of spontaneous abortion is overestimated without differential biases, the true relative risk will be in fact underestimated.

The study population was socially homogeneous, as only nursing staff were included (head nurses, registered nurses, practical nurses). Moreover restricting the analysis to the head and registered nurses did not modify the findings.

\section{Information bias}

Particular attention was given to the problem of information bias. The questionnaires were completed during interviews. The study was presented to each department concerned as a study whose purpose was to assess the reproductive characteristics in hospital personnel without focusing on any particular risk factors. Indeed, departments as different as consulting medical units and care units in oncology or cardiology were included. Finally, the questionnaire separately addressed the description of previous pregnancies on one hand and the work history of the subject on the other. With these precautions, a normal value for the frequency of spontaneous abortion among unexposed pregnancies was observed $(15.1 \%)$. Time since pregnancy was significantly different for the exposed and unexposed pregnancies. However it was not significantly related to the frequency of spontaneous abortion when considered simultaneously with cytostatic exposure and maternal age in a logistic regression.

In addition excluding spontaneous abortions corresponding to pregnancies diagnosed only by the women themselves following a late menstrual period from the analysis did not modify our results. Con- 
versely, taking the somewhat restrictive hypothesis that all women are aware of their pregnancy only after eight weeks without a menstrual period, we also restricted our analysis to spontaneous abortions occurring after eight weeks or more. Once again the results were not modified. We therefore feel that it was unlikely that the increased frequency of spontaneous abortions among the exposed pregnancies resulted from information bias.

\section{Confounders}

The frequency of spontaneous abortions in this study was significantly correlated with the classical risk factors of age at pregnancy $(20,21)$, smoking during pregnancy (22), and pregnancy order. The variations in the spontaneous abortion rate with pregnancy order has been analyzed in detail (23) and involves both direct and selection phenomena. Adjustment for these three factors either separately or simultaneously in a logistic regression did not modify the results of our study. This was also the case when we took into account occupational exposure to anesthetic agents or formaldehyde. In this study the existence of previous spontaneous abortions can be considered either as an indicator for the existence of risk factors predisposing to spontaneous abortion or, alternatively, as the first manifestation of sensitivity to cytostatic exposure. Of the 43 exposed pregnancies that were second pregnancies, 10 were preceded by one previous spontaneous abortion, and all of the earlier pregnancies that had resulted in a spontaneous abortion had been exposed. Consequently it was not possible to distinguish women who had a greater risk of spontaneous abortion from women for whom previous spontaneous abortion was the manifestation of cytostatic exposure. It was for this reason that we also decided to restrict the analysis to the first pregnancy of each woman rather than taking previous spontaneous abortions inte consideration in a multiple regression.

\section{Statistical analysis}

Taking into account all the pregnancies of each woman could place too much weight on a small number of women with a large number of spontaneous abortions. For this reason the analysis was also carried out for first pregnancies only. When the basic relationship, the relationship adjusted for classic risk factors, and the relationship studied in limited categories of spontaneous abortion were taken into consideration, a statistically significant twofold increase in the spontaneous abortion rate was observed for the exposed pregnancies as compared with the unexposed ones.

\section{Detailed analysis of exposure}

An increase in the frequency of spontaneous abortion with an increase in the frequency or duration of exposure was not observed. It must be noted however that only $25 \%$ of the exposed pregnancies were occasionally exposed. In addition no relationship with duration of exposure is to be expected if exposure during pregnancy only leads to an increase in the risk of spontaneous abortion.

It is well known that a large variety of different chemicals is used in cancer treatment. Moreover they are very often used in association with the treatment of a given patient. Consequently reliable information on the exposure of nurses to particular drugs would be very difficult to measure since the nurses handled cytostatic drugs over a long period of time and treated different types of cancer with different chemicals. For this reason we did not attempt to obtain information on specific exposure.

Selevan et al (18) was able to obtain such information. They found that the four most frequently used drugs were doxorubicin, cyclophosphamide, fluorouracil, and vincristine, and indeed they observed that the exposure of pregnancies to these four drugs were highly correlated. Attempting however to evaluate the relationship between spontaneous abortion and exposure to doxorubicin, cyclophosphamide, fluorouracil, and vincristine separately, they finally concluded that it was not possible to separate the effects of the individual drugs.

This study, together with that of Selevan et al (18), reveals a doubling in the frequency of spontaneous abortion related to exposure to cytostatic drugs in oncologic departments. This increase in risk should be confirmed in other populations.

We were only able to study general exposure to cytostatics. An interesting but difficult question would be to try to identify the most hazardous drugs among the cytostatics and the critical exposure periods.

\section{Acknowledgments}

This work was financed in part by the Ministère des Affaires Sociales et de l'Emploi (Direction des Relations du Travail) and by the Caisse Nationale d'Assurance Maladies des Travailleurs Salariés (collaboration INSERM-CNAMTS).

\section{References}

1. International Agency for Research on Cancer. Some antineoplastic and immunosuppressive agents. Lyon: International Agency for Research on Cancer, 1981. (Monographs on the evaluation of the carcinogenic risk of chemicals to humans; vol 26.)

2. Sieber SM, Adamson RH. Toxicity of antineoplastic agents in man: chromosomal aberrations, antifertility effects, congenital malformations and carcinogenic potential. Adv Cancer Res 1975;22:57-155.

3. Beeley L. Adverse effects of drugs in the first trimester of pregnancy. Clin Obstet Gynecol 1981;8(2):261-74.

4. Boros SJ, Reynolds JW. Intrauterine growth retardation following third trimester exposure to busulfan. Am J Obstet Gynecol 1977;Sept:111-2. 
5. Barlow SM, Sullivan FM. Reproductive hazards of industrial chemicals. New York, NY: Academic Press, 1982.

6. Hemminki K, Sorsa M, Vainio H. Genetic risks caused by occupational chemicals: use of experimental methods and occupational risk group monitoring in the detection of environmental chemicals causing mutations, cancer and malformations. Scand J Work Environ Health 1979; 5:307-27.

7. Benhamou S, Callais F, Sancho-Garnier H, Min S, Courtois YA, Festy B. Mutagenicity in urine from nurses handling cytostatic agents. Eur $\mathbf{J}$ Cancer Clin Oncol 1986;22(12):1489-93.

8. Bos RP, Leenars AO, Theuws JLG, Henderson PTH. Mutagenicity in urine from nurses handling cytostatic drugs, influence of smoking. Int Arch Occup Environ Health 1982;50:359-69.

9. Falk K, Gröhn P, Sorsa M, Vainio H, Heinonen E, Holsti LR. Mutagenicity in urine from nurses handling cytostatic drugs. Lancet 1979;1:1250-1.

10. Kolmodin-Hedman B, Hartvig P, Sorsa M, Falk K. Occupational handling cytostatic drugs. Arch Toxicol 1983; $54: 25-33$.

11. Stücker I, Hirsch A, Bastie-Sigeac I, Hémon D. Urine mutagenicity, chromosomal abnormalities and sister chromatid exchanges in lymphocytes of nurses handling cytostatic drugs. Int Arch Occup Environ Health 1986; 57:195-205.

12. Nikula E, Kiviniitty K, Leisti J, Taskinen PJ. Chromosomes aberrations in lymphocytes of nurses handling cytostatic agents. Scand J Work Environ Health 1984; $10: 71-4$.

13. Norppa $\mathbf{H}$, Sorsa $\mathbf{M}$, Vainio $\mathrm{H}$, et al. Increased sister chromatid exchange frequencies in lymphocytes of nurses handling cytostatic drugs. Scand J Work Environ Health 1980;67:299-301

14. Waksvik H, Klepp O, Brogger O. Chromosome analyses of nurses handling cytostatic agents. Cancer Treat Rep $1981 ; 65: 607-10$.

15. MCDonald AD, McDonald JC, Armstrong B, et al. Fetal deaths and work in pregnancy. $\mathrm{Br} \mathrm{J}$ Ind Med 1988;45: $148-57$.

16. Taskinen H, Lindbohm ML, Hemminki K. Spontaneous abortions among women working in the pharmaceutical industry. $\mathrm{Br} \mathrm{J}$ Ind Med 1986;43:199-205.

17. Hemminki K, Kyyrönen P, Lindbohm ML. Spontaneous abortions and malformations in the offspring of nurses exposed to anaesthetic gases, cytostatic drugs, and other potential hazards in hospitals, based on registered information of outcome. J Epidemiol Community Health $1985 ; 39: 141-7$.

18. Selevan S, Lindbohm ML, Hornung RW, Hemminki K. A study of occupational exposure to antineoplastic drugs and fetal loss in nurses. N Engl J Med 1985;313(19): $1173-8$.

19. Axelsson G. Selection bias in studies of spontaneous abortions among occupational groups. J Occup Med 1984;26(7):525-8.

20. Harlap S, Shiono PH, Ramcharan S. A life table of spontaneous abortions and the effects of age, parity, and other variables. In: Porter IH, Hook EB, ed. Human embryonic and fetal death. New York, NY: Academic Press, 1980:145-58.

21. Stein Z, Kline J, Susser E, Shrout P, Warburton D, Susser M. Maternal age and spontaneous abortion. In: IH Porter, EB Hook, ed. Human embryonic and fetal death. New York, NY: Academic Press, 1980:107-27.

22. Kline J, Stein Z, Susser M, Warburton D. Environmental influences on early reproductive loss in a current New York city study. In: Porter IH, Hook EB, ed. Human embryonic and fetal death. New York, NY: Academic Press, 1980:225-40.

23. Roman E, Alberman E. Spontaneous abortion, gravidity, pregnancy order, age, and pregnancy interval. In: Porter IH, Hook EB, ed. Human embryonic and fetal death. New York, NY: Academic Press, 1980: $129-43$.

Received for publication: 28 July 1989 